\title{
Grid Interactive Solar Powered Automated Bottling Plant Using Microcontroller
}

Authors: $\quad$ Rupal Srivastava

Dept. ECE, National Institute of Technology, Jamshedpur, India

e-mail:12rupal12@gmail.com

Niraj Kumar

Dept. ECE, National Institute of Technology, Jamshedpur, India e-mail: nirajmodiece@gmail.com

Anjali Barnwal

Dept. ECE, National Institute of Technology, Jamshedpur, India e-mail: anjalibarnwal480@gmail.com

Shiva Nand Singh

Dept. ECE, National Institute of Technology, Jamshedpur, India e-mail: snsingh.ece@nitjsr.ac.in

Subject Category: Engineering

Sub Category: Embedded System

\section{Editor: M. Mukherjee}

Volume 2 Issue 1 January 2017

Received on: 07.01.2017

Revised on: 15.01.2017
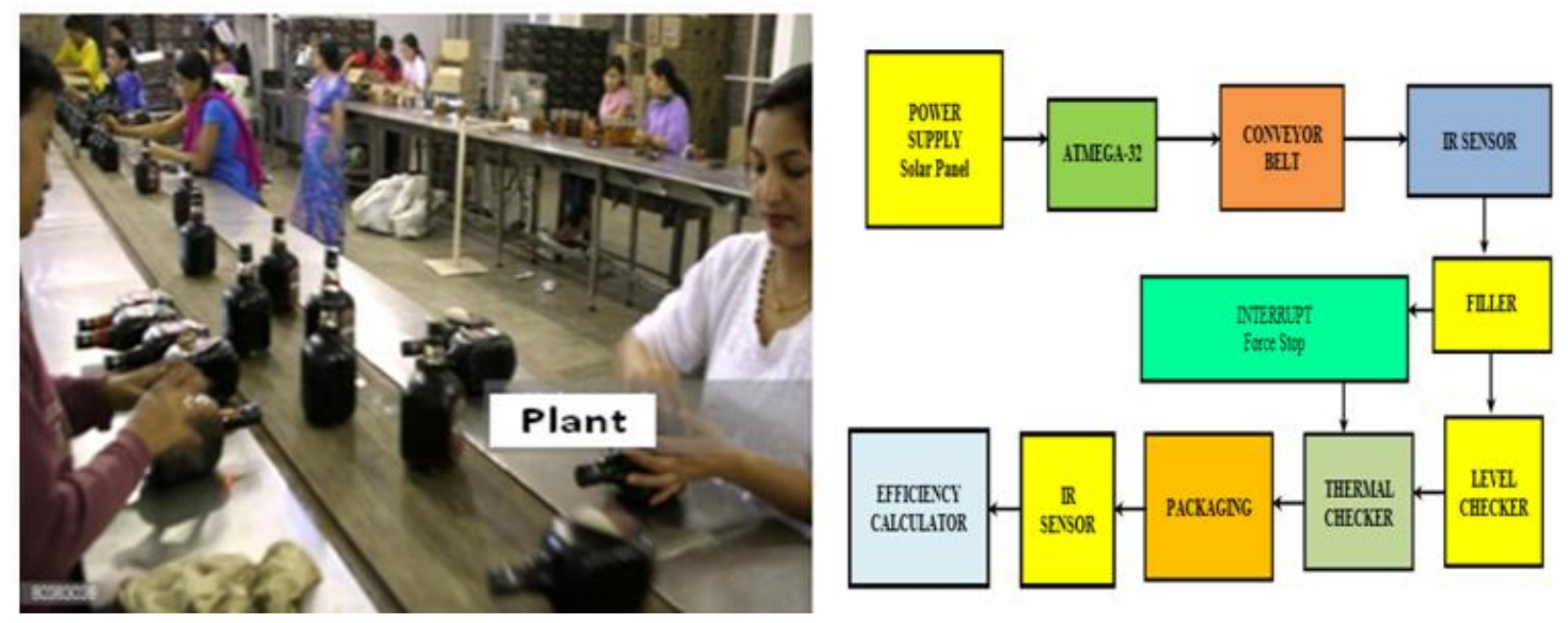

Keywords:

Automatic bottle filling;

Bottling plant system;

Grid interactive solar power supply;

Microcontroller based bottle filling;

Process automation.

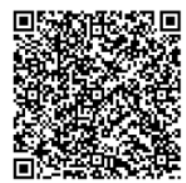

Rupal Srivastava, Niraj Kumar, Anjali Barnwal and Shiva Nand Singh, "Grid Interactive Solar Powered Automated Bottling Plant Using Microcontroller," International Journal of Advanced Engineering and Management, Vol. 2, No. 1, pp. 9-14, 2017. 


\title{
Grid Interactive Solar Powered Automated Bottling Plant Using Microcontroller
}

\author{
Rupal Srivastava, Niraj Kumar, Anjali Barnwal and Shiva Nand Singh
}

\begin{abstract}
In this study, attempt has been made to develop digital controller using a microcontroller to automate the bottling plant and to make it user-friendly for village entrepreneur of our country to increase the production of bottles filled with edible oils, country liquor alcohol, mustered oils, fruit juice, Jam, and Jelly, etc. In this era of rural industrialization, technological revolution/automation conventional plants with the manual bottle filling system are shrinking day by day due to high cost, low efficiency. As a result, the need for automated machinery is increasing in a very fast manner. To hold out the commitment of timely delivery of product and to meet the demand, hi-tech automated production even in rural areas has become essential. The grid interactive $1 \mathrm{~kW}$ solar power supply as provided by the rural grid for $24 \times 7$ days ensures the continuous production of this product. The field of automation has a notable impact in the rural society of our country. The design of the controller for automated bottling plant with limited capacity with 200 bottle capacity per shift in a day using microcontroller ATMEGA32, have been developed. The simulation study of functional and operational test on prototype unit has been performed, and the results have been found an encouraging one. The cost economy of prototype unit has been computed and analyzed, and the impact study has been carried out in rural society.
\end{abstract}

\section{Introduction}

Beverage markets offer opportunities that can be transformed into success only by those Industries that have a technology to take it beyond competition [1]. In small industries, the bottling process is either manual or semiautomatic. This process can have shortcomings like spilling of liquid while filling it in bottle, unequal quantity of liquid in different bottle and reduced efficiency due to human errors [2]. The current scenario is to embrace new technologies to proceed towards automation for precise filling. To meet the customers demand and accelerate the filling of bottles, all operations are nearly automated. New technologies with automation will reduce wastage, increase efficiency and minimize downtime in high-speed beverage production environment [3]. The automation of bottle filling as used in big Industry involves the use of PLC for control but this is a bit costly.

In small industries located in rural areas, bottle fillings plants are operated manually by semi-skilled villages only. The manual filling process has many shortcomings like spilling of liquid while filling it in bottle, equal quantity of liquid may not be filled, delay due to natural activities of human etc. The automation in bottle filling industry comes with modular components [4]. Essential requirements of each module in the system are important to be studied in order to understand how each part of system module works in coordination with other modules in the system [5]. The main unit is control system which includes C programming in ATMEGA32 microcontroller to control various modules of plant. A conveyor system with sensors and valves is fabricated for this purpose. This proposed system is meant for small a industry which aims to eliminate problem as faced by small scale bottle filling system. With this system which operates automatically, every process can be smooth and the process of refilling can reduce worker cost and operational cost.

In order to get an idea on the basic fundamentals in the present study, an extensive literature review has been carried out. Rajesh G. Khatod, Chandra Shekhar Sakhale [6] in their papers worked on touch screen operated liquid dispenser machine for chemical, pharmaceutical industries. The research paper emphasized on reducing complexity and the cost involved in present liquid dispenser machine. The research paper aimed to improve metering quality of dispenser machine. The microcontroller used in this system was AT89C52. The system is controlled by microcontroller programming. Also, the research paper gives information about working of system and measurement of process variables. A.S.C.S Sastry, K.N.H. Srinivas [7] in their research paper introduced a systematic approach to design and realize a temperature and volume based liquid mixing system using three low cost microcontrollers. The primary function of this system is to mix different liquids of required ratio and

Rupal Srivastava, Niraj Kumar, Anjali Barnwal and Shiva Nand Singh, "Grid Interactive Solar Powered Automated Bottling Plant Using Microcontroller," International Journal of Advanced Engineering and Management, Vol. 2, No. 1, pp. 9-14, 2017. 
temperature. In this paper the electronic sub system is developed with the help of three AT89S51 microcontrollers for controlling. The system has two LM35 sensors which are used for sensing temperature. The mechanical sub system consists of two geared DC motors to allow the liquids in required ratio for mixing [8].

In the present system as proposed, the study emphasizes on the use of ATMEGA32 microcontrollers which is heart of the system. The entire sequence of operation is controlled by the microcontroller. They are relatively cheap and easily available. The system developed in this innovative work is a complete package of automated filling management system. It provides flexibility, reliability, ability to modify and extend an existing plant and monitoring of the entire plant. The system as proposed meets the demand of high-speed production using the least mechanism requirements. The system has proved to work effectively avoiding unnecessary spill or wastage of liquids.

The paper has been discussed mainly in four sections. The first section gives the introduction followed by system description and flow chart (algorithm) of control scheme as described in second section. The third section gives the analysis and finally the conclusions are given in section four.

\section{System description}

\section{a) System Module}

The block diagram consists of the following modules: (i) Grid interactive solar power supply unit, (ii) Microcontroller ATMEGA-32, (iii) Conveyor belt, (iv) IR sensors module, (v) Filler, (vi) Level checker unit, (vii) Thermal sensors, (viii) Packaging unit, (viii) Efficiency calculator and display unit etc. Which are shown in the Fig. 1.

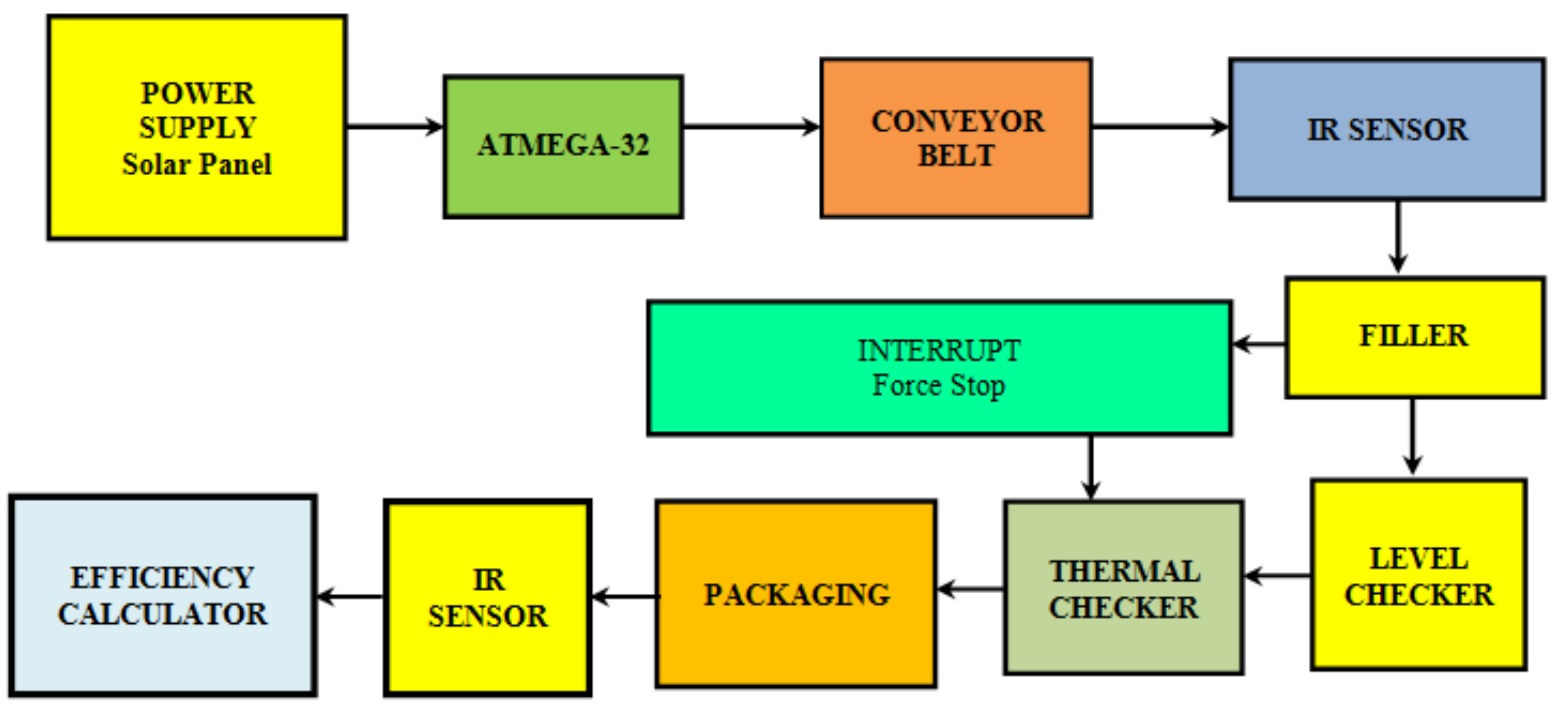

Figure 1. Block schematic diagram of the bottling plant system.

\section{b) Working Plan and Design Feature of the Proposed System}

The power supply switches on ATMEGA-32 Micro controller. Schematic diagram (Fig. 2) of the grid interactive solar power supply [9] for $24 \mathrm{hr}$ x7days unit are shown here [10]. This drives the conveyor belt and thus the bottles move on the conveyer belt. The IR Sensor senses the presence of bottle and the belt stops at the marked position. The filler fills the bottle and level of liquid senses by level checker and if found proper within tolerable limit the same passes on to a thermal checker. This checks the quality of the filling bottles and then passes on to the packaging unit. The IR sensor at the end counts the number of bottles and this in turn is used to calculate the efficiency indicating the number of bottles filled properly at the end.

The system is designed to display indication at various operational stages. Before the belt starts, there is a yellow signal which indicates that the belt is about to start. If the belt is in motion, there is green light which glows. When the belt stops and the filling process occur, the red light glows. Apart from this normal functioning of the system, there is a possibility of any unwanted phenomenon to occur for this, an interrupt signal is raised. When an external interrupt is raised, the belt stops and the blue light glows during the duration of interrupt. Once the interrupt is raised the faulty bottle is removed and the normal filling continues.

Rupal Srivastava, Niraj Kumar, Anjali Barnwal and Shiva Nand Singh, "Grid Interactive Solar Powered Automated Bottling Plant Using Microcontroller," International Journal of Advanced Engineering and Management, Vol. 2, No. 1, pp. 9-14, 2017. 


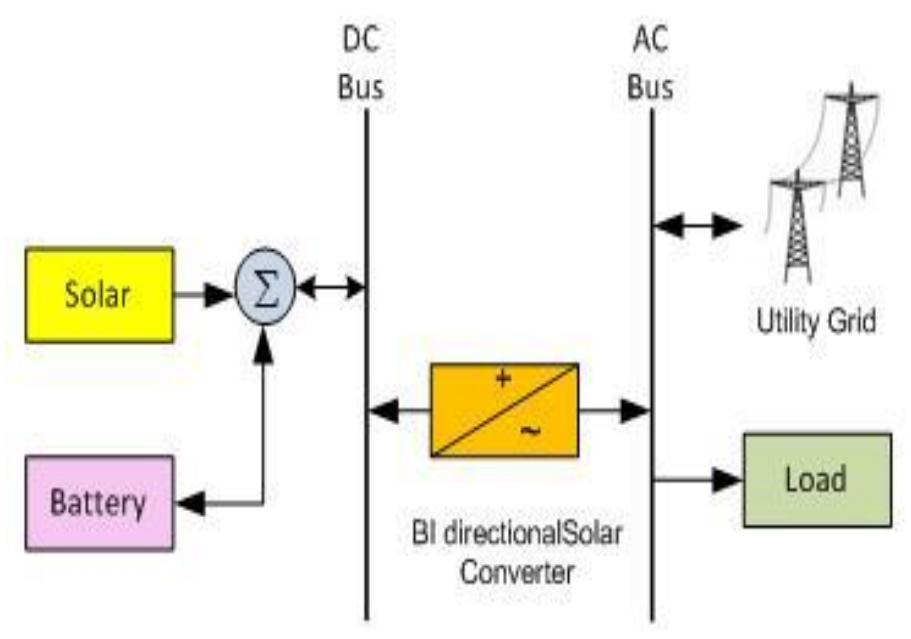

Figure 2. Schematic diagram of the grid interactive solar power supply.

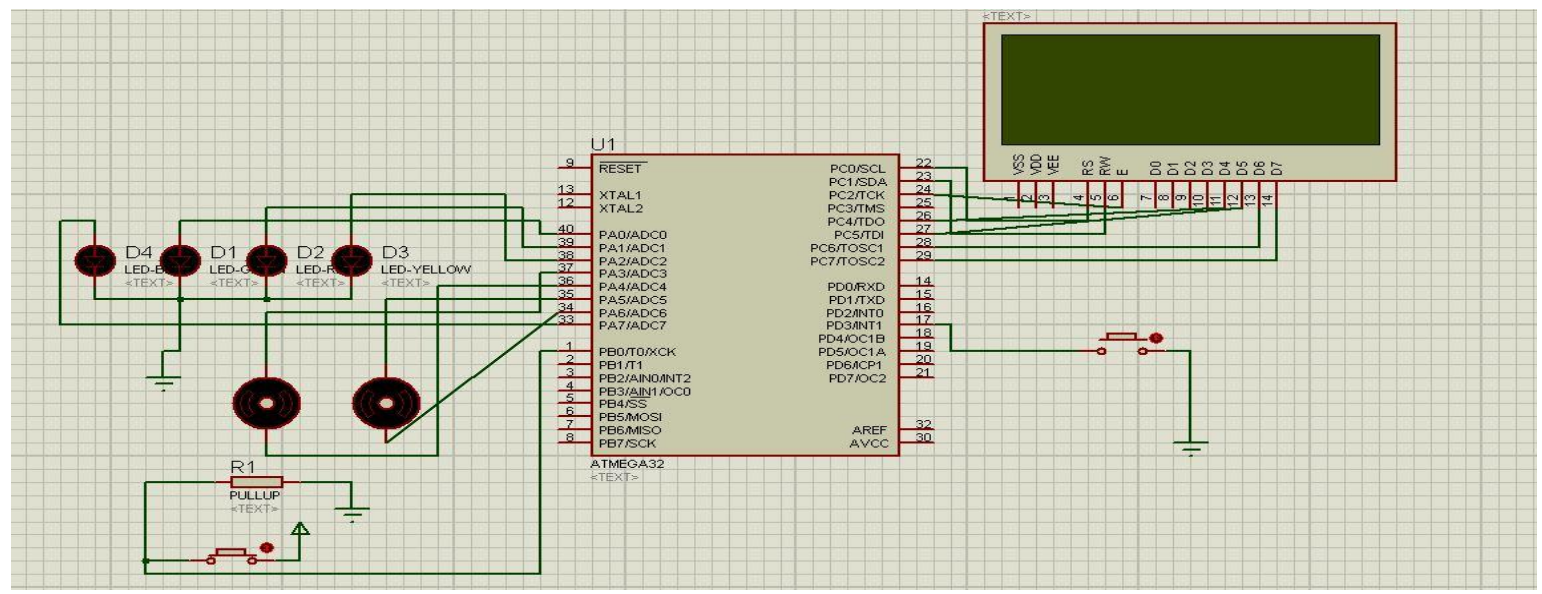

Figure 3. Simulation circuit and proposed bottling plant

\section{c) System Specifications of Proposed Plant}

(i). Bottling Capacity : 200 Bottles per day in one unit

(ii). Room size: $10 \times 15$ feet

(iii). Weight : Assorted (180 - 500ml)

(iv). Power supply : 1kW Solar Power with grid assisted (24x7) [11]

(v). Manpower : 5 per unit per shift

(vi). Cost : affordable by villagers

Microcontroller based Simulation circuit and proposed bottling plant is shown in Fig. 3.

\section{Control Algorithm}

The algorithm has been developed to monitor desired sequence of control in a proposed $\mathbf{2 0 0}$ capacity bottling plant as depicted below:

Step 1: Start: Power supply as initiated for a delay of 5 second is switched ON for start.

Step 2: Feeding: Rotate the DC motor for bottle feeding.

Step 3: Filling: Sensing the bottle and IR sensor counts the number, Open solenoid valve, Delay 10S.

Step 4: Level checker: Checks the level of liquid in the bottle.

Step 5: Thermal Sensor : Checks for any interrupt for quality of liquid filled.

Step 6: Capping: Bottles are capped and an IR sensor counts the number of bottles output.

Step 7: Efficiency calculation: Display on LCD Panel.

Rupal Srivastava, Niraj Kumar, Anjali Barnwal and Shiva Nand Singh, "Grid Interactive Solar Powered Automated Bottling Plant Using Microcontroller," International Journal of Advanced Engineering and Management, Vol. 2, No. 1, pp. 9-14, 2017. 


\section{Results Analysis and Discussion}

The observations as recorded on the below mentioned parameters during study as carried out on prototype plant are as follows:

\section{a) Frequency of Breakdown and MTBF}

In a bottling plant, a number of bottles are broken during the filling process. Therefore it is necessary to keep a count of the final number of bottles processed and accordingly the performance of the system is evaluated. The above system gives an analysis of the number of bottles packed and it also calculates the efficiency of the system. The data as acquired during trial of proposed plant is computed for efficiency using the formula as shown below: Efficiency $=($ OUTPUT $/$ INPUT $) * 100 \%$

(Where, Number of bottles sent for filling as counted by the IR sensor at input $=200$

Number of bottles capped and labelled as counted by the output IR Sensor $=192$ )

$$
\begin{aligned}
& =(192 / 200) * 100 \% \\
& =96 \%
\end{aligned}
$$

MTBF is expected as very low and production target may achieve cent percent.

\section{b) Quality Check}

The system also provides for quality check at every stage while filling the bottles. The temperature at which the bottles are packed is around $\mathbf{2 - 3}$ degree Celsius. The quality checker does the task to ensure this temperature.

\section{c) Emergency Operational Switches}

It also has a provision for interrupts in case any unwanted phenomenon arises in the filling process. The thermal sensor checks for such interrupts and stops the conveyor belt. This helps in the removal of faulty bottles. The system also provides sufficient delay between various stages so as to ensure smooth running of the system.

\section{d) Application}

The proposed automated bottle filling system may find its application in the following areas such as :

- Fully automatic cold drink filling system

- Edible oil like mustered oil, coconut oil etc.

- Pharmaceutical industry

- Jam, jelly, fruit juice and sauce cottage industry

- Milk filling system

- Alcohol, beer and country liquor bottle filling plant

- Mineral drinking water bottle filling system etc.

\section{Conclusion}

This paper suggested a design of controller of bottling plant based on digital technology using a Microcontroller ATMEGA-32. The production yield has increased due to automation as adopted in filling of bottles with raw material. In the present study, sequential operation i.e. feeding, bottle filling, capping and packing operations were programmed in microcontroller and simulation study were carried out, tested and found in order. The manpower utilization has been reduced $50 \%$ and the performance achieved near about sent percent. Achieved The feasibility study, impact of installation of such bottling plant with grid interactive power supply and its utilization in rural sector was further studied and it is anticipated that the employment opportunity by setting up such plant in rural sector will increase in near future under Start Up Scheme and other sponsored scheme of Govt. of India.

\section{References}

[1] B. Mashilkar, P. Khaire and D. Girish, "Automated Bottle Filling System," International Research Journal of Engineering and Technology, vol. 2, no. 7, pp. 771-776, 2015.

[2] H. Ahuja, A. Singh, S. Tandon, S. Srivastava and S. Pal, "Automatic Filling Management System for Industries," International Journal of Emerging Technology and Advanced Engineering, vol. 4, no. Sp 1, pp. 241-244, 2014.

[3] O. Mohamed, A. Adlan and A. J. Alzubaidi, ISR Journal of Engineering, vol. 5, no. 2, pp. 37-41, 2015.

Rupal Srivastava, Niraj Kumar, Anjali Barnwal and Shiva Nand Singh, "Grid Interactive Solar Powered Automated Bottling Plant Using Microcontroller," International Journal of Advanced Engineering and Management, Vol. 2, No. 1, pp. 9-14, 2017. 
[4] M. Demetgul, M. Unal, I. N. Tansel and O. Yazıcığlu, "Fault Diagnosis on Bottle Filling Plant Using Genetic-Based Neural Network," Advances in Engineering Software, vol. 42, no. 12, pp. 1051-1058, 2011.

[5] A. P. Somawanshi, S. B. Asutkar and S. A. More, "Automated Bottle Filling Using Microcontroller Volume Correction," International Journal of Engineering Research and Technology, vol. 2, no. 3, pp. 1-4, 2013.

[6] R. G. Khatod and C. S. Sakhale, "Design \& Fabrication of Liquid Dispensing Machine Using Automatic Control for Engg. Industry," International Journal of Innovative Technology and Exploring Engineering, vol. 1, no. 5, pp. 38-44, 2012.

[7] A. S. C. S. Sastry, K. N. H. Srinivas, C. V. S. R. G. Krishna and C. KiranKumar, "An Automated Microcontroller Based Liquid Mixing System," International Journal on Computer Science and Engineering, vol. 2, no. 8, pp. 2648-2651, 2010.

[8] T. Kalaiselvi, R. Praveena, R. Aakanksha and S. Dhanya, "PLC Based Automatic Bottle Filling and Capping System With User Defined Volume Selection," International Journal of Emerging Technology and Advanced Engineering, vol. 2, no. 8, pp. 134-137, 2012.

[9] S. N. Singh, "FGPA based Sinusoidal Pulse width Modulated Waveform Generator for Solar (PV) Rural Home Power Inverter,” Journal of Telecommunication, vol. 1, no. 1, pp. 72-79, 2010.

[10] S. N. Singh and A. K. Singh, "Simulation of Grid-Assisted Solar Power Converters: An Effective Solution for Power Crisis in Rural India," Asian Journal on Energy and Environment, vol. 2, pp. 96-102, 2011.

[11] S. N. Singh and A. K. Singh, "Solar (PV)-Grid/DG Green Power Supply for Rural India,” JEE, vol. 10, pp. 36-40, 2010.

Rupal Srivastava, Niraj Kumar, Anjali Barnwal and Shiva Nand Singh, "Grid Interactive Solar Powered Automated Bottling Plant Using Microcontroller," International Journal of Advanced Engineering and Management, Vol. 2, No. 1, pp. 9-14, 2017. 